\title{
Research
}

\section{Do English patients want continuity of care, and do they receive it?}

\author{
Abstract

\section{Background} \\ Interpersonal continuity of care is valued by \\ patients, but there is concern that it has declined \\ in recent years. \\ Aim \\ To determine how often patients express \\ preference for seeing a particular GP and the \\ extent to which that preference is met.

\section{Design of study} \\ Analysis of data from the 2009/2010 English GP \\ Patient Survey.

\section{Setting} \\ A stratified random sample of adult patients \\ registered with 8362 general practices in England \\ (response rate 39\%, yielding 2169718 \\ responses).

\section{Method} \\ Weighted estimates were calculated of \\ preference for and success in seeing a particular \\ GP. Multilevel logistic regression was used to \\ identify characteristics associated with these two \\ outcomes.

\section{Results} \\ Excluding practices with one GP, $62 \%$ of patients \\ expressed a preference for seeing a particular \\ GP. Of these patients, $72 \%$ were successful in \\ seeing their preferred GP most of the time. \\ Certain patient groups were associated with \\ more preference for and success in seeing a \\ particular GP. These were older patients \\ (preference odds ratio $[O R]=1.7$, success $O R=$ \\ 1.8), those with chronic medical conditions \\ (preference $\mathrm{OR}=1.9$, success $\mathrm{OR}=1.3$ ), those \\ with chronic psychological conditions (preference \\ $\mathrm{OR}=1.6$, success $\mathrm{OR}=1.3$ ), and those recently \\ requesting only non-urgent versus urgent \\ appointments (preference $\mathrm{OR}=1.4$, success $\mathrm{OR}=$ \\ 1.6). Patient groups that had more frequent \\ preference but less success in seeing a preferred \\ GP were females (preference OR $=1.5$, success \\ $\mathrm{OR}=0.9$ ), patients in larger practices (preference \\ $\mathrm{OR}=1.3$, success $\mathrm{OR}=0.5$ ), and those belonging \\ to non-white ethnic groups.
}

\section{Conclusion}

The majority of patients value interpersonal continuity, yet a large minority of patients and specific patient groups are not regularly able to see the GP they prefer.

\section{Keywords}

continuity of patient care; England; general practice; primary healthcare.

\section{INTRODUCTION}

There are a number of dimensions of continuity of care..$^{1-6}$ A widely used classification identifies three types of continuity, namely informational, management, and interpersonal lor relational) continuity (Box 1).

Studies from different countries suggest that interpersonal continuity of care is highly valued by patients, especially by females, older patients, and those with chronic disease. ${ }^{7.8}$ Continuity of care is associated with improved patient outcomes 9,10 and increased patient satisfaction. ${ }^{11-13}$ However, interpersonal continuity has declined in recent years in the UK and in other countries. ${ }^{14-16}$ This decline may reflect increasing emphasis on technical (clinical) aspects of primary care quality, as well as a reduction in doctors working hours, an increase in part-time working, and organisational changes in out-of-hours care.

\section{METHOD}

Data

Data from the 2009/2010 English General Practitioner Patient Survey (GPPS) were analysed; the GPPS is a national questionnaire survey covering different aspects of patient experience, sent by post to a stratified random sample of adult patients registered with an English primary care practice. In 2009/2010, the questionnaire

A Aboulghate, MBChB, MPhil, PhD student G Abel, PhD, research associate, statistician; RA Parker, MSc, research assistant;

G Lyratzopoulos, MD, clinical senior research associate; M Roland, DM, professor of health services research, Cambridge Centre for Health Services Research, University of Cambridge Institute of Public Health, Cambridge. MN Elliott, PhD, senior statistician, RAND Corporation, Santa Monica, CA, US. J Campbell, MD, professor of general practice and primary care, Peninsula College of Medicine and Dentistry, Exeter. was sent to 5.5 million individuals. 17,18 Results of the survey are reported publicly for all practices. To ensure a minimum number of responses per practice, practices serving small populations and practices that were likely to have low response rates were oversampled. ${ }^{19}$

In the GPPS, continuity of care was assessed by two questions focusing on preference for and success in seeing a preferred doctor (Box 2).

Using data provided by the survey responders, associations between these two measures of continuity of care and patient age, sex, ethnicity (16 categories as defined by the Office for National Statistics), and self-reported chronic medical or psychological/emotional condition were examined. Associations with patient deprivation (Index of Multiple Deprivation 2007, based on the patient's postcode ${ }^{21}$ and the number of non-trainee GPs in each practice (as a marker of practice size) were also examined, using data from the $2009 \mathrm{GP}$ census provided by the NHS Information Centre. Finally, associations with types of appointments requested in the previous 6 months, as reported by patients, were examined using a four-category classification; that is, whether the appointment(s) they had tried to make were urgent (within 2 working days) or nonurgent (after more than 2 working days), or both, or neither.

\section{Address for correspondence}

Ahmed Aboulghate, Cambridge Centre for Health Services Research, University of Cambridge, Institute of Public Health, Forvie Site, Robinson Way, Cambridge, CB2 OSR

E-mail: aa577amedschl.cam.ac.uk

Submitted: 9 December 2011; Editor's response: 8 January 2012; final acceptance: 31 January 2012. (CBritish Journal of General Practice

This is the full-length article (published online $30 \mathrm{Jul}$ 2012) of an abridged version published in print. Cite this article as: Br J Gen Pract 2012; DOI: 10.3399/bjgp12X653624. 


\section{How this fits in}

Previous studies suggest that patients value interpersonal continuity of care, but this preference varies in different patient groups. This study shows that $62 \%$ of primary care patients in England express a preference for seeing a particular doctor. Patients who were more likely to have such a preference were found to be females, older patients, those with chronic medical or psychological/emotional conditions, and patients of non-white ethnic origin. However, more than one-quarter of patients who prefer to see a particular doctor do not succeed in doing so most of the time. This study provides evidence that continuity of care is valued by the majority of patients. More needs to be done to meet these aspirations, especially in the light of evidence that continuity of care has declined in general practice in recent years.

\section{Analysis}

Responses to how often patients were able to see their preferred doctor (where they expressed a preference for doing sol were dichotomised into a yes ('always or almost always' or 'a lot of the time')/no ('some of the time' or 'never or almost never') measure.

Survey weights were developed by Ipsos MORI (the survey provider) and were used in the analysis to account for the complex survey design and non-response in prevalence estimates of preference for and success in seeing a preferred doctor. These

\section{Box 1. Types of continuity of care ${ }^{1}$}

- Informational continuity: the use of information on past events and personal circumstances to make current care appropriate for each individual

- Management continuity: a consistent and coherent approach to the management of a health condition that is responsive to a patient's changing needs.

- Interpersonal (relational) continuity: an ongoing therapeutic relationship between a patient and one or more providers.

\section{Box 2. Questions on continuity of care as they appear in the 2009/2010 GPPS questionnaire ${ }^{20}$}

Q15. Is there a particular doctor you prefer to see at your GP surgery or health centre?

Yes ..... Please go to Q16

No ..... Please go to Section F

There is usually one doctor in my GP surgery or health centre ..... Please go to section F

Q16. How often do you see the doctor you prefer to see?

Always or almost always

A lot of the time

Some of the time

Never or almost never

Not tried at this GP surgery or health centre weights employed rim weighting with two rims: (a) age-by-sex (8*2 levels), and (b) practice (8362 levels). ${ }^{19}$

Crude and multivariate logistic regression models were used to examine the association between various patient and practice characteristics and preference for and success in seeing a preferred doctor, separately. The data were adjusted for sex, age group, ethnicity, deprivation quintile, self-reported chronic medical or psychological/emotional condition, number of practice doctors, and type of appointments requested by the patient in the previous 6 months.

Crude models made use of the weights and adjusted standard errors to account for the survey design. Multivariate models did not make use of the weights but did include random intercepts for practice to account for clustering of patients within practices and to better distinguish the experiences and preferences of patient subgroups from general variation in continuity at practice level.

Although patient registration with a given practice is largely determined by geographical proximity, some patients might choose to register with a smaller practice specifically to get better continuity of care, in which case it would not have been appropriate to adjust sociodemographic associations for practice size. For this reason, a sensitivity analysis was performed, excluding the number of practice doctors. The results were very similar, so the data are not shown.

Stata (version 11) was used for the descriptive analyses and SAS (version 9.2) for the regression analyses.

\section{RESULTS}

The overall response rate was 39\%, with 2169718 completed responses from patients in 8362 practices. ${ }^{17,18}$ The sociodemographic characteristics of responders are shown in Table 1.

Preference for seeing a particular doctor Two per cent of patients reported that there was only one GP in their practice. After excluding those patients from further analysis, $62 \%$ of patients reported having a preference for seeing a particular doctor (Table 2). Such a preference varied across patient groups (Table 2) and was higher in females $(68 \%$ versus $56 \%$ in males), older patients $152 \%$ for age group $18-24$ years, increasing to $81 \%$ for the age group 75-84 years), those with chronic medical or psychological/emotional conditions $175 \%$ and $78 \%$ respectivelyl compared to those 
without chronic conditions $152 \%$ and $61 \%$ respectivelyl, and those living in more affluent areas (from $60 \%$ to $64 \%$ for patients

Table 1. Demographic characteristics of responders to the 2009/2010 General Practice Patient Survey

\begin{tabular}{|c|c|c|}
\hline Characteristic & $n$ & $\%$ \\
\hline All survey responders & 2169718 & 100 \\
\hline \multicolumn{3}{|l|}{ Sex } \\
\hline Male & 897326 & 42.4 \\
\hline Female & 1218009 & 57.6 \\
\hline \multicolumn{3}{|l|}{ Age group, years } \\
\hline $18-24$ & 103865 & 4.9 \\
\hline $25-34$ & 230654 & 10.9 \\
\hline $35-44$ & 326488 & 15.5 \\
\hline $45-54$ & 376472 & 17.8 \\
\hline $55-64$ & 428774 & 20.3 \\
\hline $65-74$ & 357022 & 16.9 \\
\hline $75-84$ & 223834 & 10.6 \\
\hline$\geq 85$ & 66621 & 3.2 \\
\hline \multicolumn{3}{|l|}{ Ethnic group (ONS 6) $\quad$ Ethnic group (ONS16) } \\
\hline White British & 1746425 & 82 \\
\hline Irish & 28805 & 1.4 \\
\hline Any other white & 86278 & 4.1 \\
\hline White and Black Caribbean & 4345 & 0.2 \\
\hline White and Black African & 2808 & 0.1 \\
\hline White and Asian & 4182 & 0.2 \\
\hline Any other mixed & 5046 & 0.2 \\
\hline South-Asian & 53464 & 2.6 \\
\hline Pakistani & 29056 & 1.4 \\
\hline Bangladeshi & 9711 & 0.5 \\
\hline Any other Asian & 21270 & 1.0 \\
\hline Black Caribbean & 24095 & 1.1 \\
\hline Black African & 29936 & 1.4 \\
\hline Any other black & 4750 & 0.2 \\
\hline Chinese & 10007 & 0.5 \\
\hline Other ethnic group & 69665 & 3.3 \\
\hline \multicolumn{3}{|l|}{ Deprivation quintile } \\
\hline 1 (affluent) & 387771 & 17.9 \\
\hline 2 & 418707 & 19.3 \\
\hline 3 & 430329 & 19.9 \\
\hline 4 & 446263 & 20.6 \\
\hline 5 (deprived) & 483594 & 22.3 \\
\hline \multicolumn{3}{|l|}{ Presence of self-reported chronic medical condition } \\
\hline No & 948565 & 49.9 \\
\hline Yes & 951323 & 50.1 \\
\hline \multicolumn{3}{|c|}{ Presence of self-reported long-standing psychological or emotional condition } \\
\hline No & 1792622 & 94.2 \\
\hline Yes & 110507 & 5.8 \\
\hline \multicolumn{3}{|l|}{ Number of practice GPs } \\
\hline 1 & 259957 & 12.1 \\
\hline 2 & 347707 & 16.2 \\
\hline 3 & 285727 & 13.3 \\
\hline 4 & 281408 & 13.1 \\
\hline 5 & 257185 & 11.9 \\
\hline $6-9$ & 651996 & 30.2 \\
\hline$\geq 10$ & 72390 & 3.4 \\
\hline \multicolumn{3}{|l|}{ Type of appointments sought in previous 6 months ${ }^{a}$} \\
\hline No appointments requested & 570480 & 26.3 \\
\hline Urgent only & 554818 & 25.6 \\
\hline Non-urgent only & 271794 & 12.5 \\
\hline Both urgent and non-urgent & 772626 & 35.6 \\
\hline
\end{tabular}

ONS = Office for National Statistics. ${ }^{a}$ As reported by the patients (see Method). from the most to the least deprived areas).

Patients' preference for seeing a particular doctor ranged from $47 \%$ to $65 \%$ of responders across the 16 ethnic groups, and increased with the number of practice GPs $158 \%$ for practices with two GPs, increasing to $63 \%$ for practices with six to nine GPs). Preference for seeing a particular doctor was higher in patients who had requested only non-urgent appointments in the previous 6 months (68\%) compared to patients who had requested only urgent appointments (58\%). The crude odds ratios (Table 2 ) reflect the associations described above. All associations are stronger than would be expected by chance $(P<0.001)$.

In multivariate analysis, there was strong evidence that differences exist in the preference for seeing a particular doctor across all sociodemographic groups after adjusting for other factors $(P<0.001$ for all variables) (Table 2). This preference was more common among females lodds ratio $[O R]=1.50)$, older people $(O R=1.71$ for age group 74-85 years compared to age group 55-64 years), responders suffering from a chronic medical $(O R=1.87)$ or psychological/emotional condition $10 \mathrm{R}=$ 1.59), and those from more affluent areas $\mathrm{OOR}=0.84$ for most deprived compared to most affluent areas). Patients from SouthAsian ethnic groups (Bangladeshi, Indian, Pakistani and 'any other Asian') had substantially higher preference for seeing a particular doctor $[\mathrm{OR}=1.74,1.49,1.49$, and 1.28 respectively, compared to white British). Patients were more likely to express such preference if they were registered with practices with a greater number of GPS $10 R=1.3$ for patients registered with practices with six to nine GPs compared to patients registered with practices with two GPs) and if they had sought non-urgent appointments $(\mathrm{OR}=1.4$ patients seeking non-urgent appointments only compared to patients seeking urgent appointments only).

\section{Success in seeing a preferred doctor}

Subsequent analysis is restricted to patients with a preference for seeing a particular doctor. Of these patients, $72 \%$ were successful in seeing the doctor they preferred 'always or almost always' or 'a lot of the time': those two response categories are referred to using the term 'most of the time' hereafter (Table 3). The proportion of patients who were successful in seeing their preferred GP most of the time was higher in males $(74 \%$ versus $70 \%$ in females), older 
patients $160 \%$ for age group 18-24 years,

increasing to $87 \%$ for age group $75-84$ years), and those with chronic medical or psychological/emotional conditions $177 \%$

Table 2. Prevalence and odds ratios for having a preference for seeing a particular doctor

\begin{tabular}{|c|c|c|c|}
\hline Characteristic & $\begin{array}{c}\text { Weighted prevalence } \\
\qquad(95 \% \mathrm{CI})\end{array}$ & $\begin{array}{l}\text { Crude weighted } \\
\text { OR }^{\mathrm{a}}(95 \% \mathrm{Cl})\end{array}$ & $\begin{array}{l}\text { Adjusted OR } \\
\text { (95\% CI) }\end{array}$ \\
\hline All survey responders & 62.2 (61.9 to 62.4 ) & N/A & N/A \\
\hline \multicolumn{4}{|l|}{ Sex } \\
\hline Male & 56.3 (56.1 to 56.6 ) & Reference & Reference \\
\hline Female & 67.5 (67.2 to 67.7$)$ & $1.60(1.59$ to 1.61$)$ & 1.50 (1.49 to 1.52 ) \\
\hline \multicolumn{4}{|l|}{ Age group, years } \\
\hline $18-24$ & 51.7 (51.1 to 52.2 ) & $0.49(0.48$ to 0.50$)$ & 0.65 (0.64 to 0.66$)$ \\
\hline $25-34$ & 51.0 (50.6 to 51.3 ) & $0.48(0.47$ to 0.48$)$ & 0.55 (0.54 to 0.56$)$ \\
\hline $35-44$ & 56.0 (55.6 to 56.3 ) & 0.58 (0.58 to 0.59 ) & $0.66(0.65$ to 0.67$)$ \\
\hline $45-54$ & 61.4 (61.1 to 61.7 ) & 0.73 (0.72 to 0.74$)$ & 0.79 (0.78 to 0.80$)$ \\
\hline $55-64$ & $68.6(68.3$ to 68.9$)$ & Reference & Reference \\
\hline $65-74$ & 76.0 (75.8 to 76.3 ) & 1.45 (1.44 to 1.47$)$ & 1.36 (1.35 to 1.38$)$ \\
\hline $75-84$ & 81.1 (80.8 to 81.4 ) & 1.97 (1.94 to 2.00$)$ & 1.71 (1.69 to 1.74$)$ \\
\hline$\geq 85$ & $80.0(79.5$ to 80.4$)$ & 1.83 (1.78 to 1.88 ) & 1.54 (1.50 to 1.58$)$ \\
\hline Ethnic group (ONS16) & & & \\
\hline \multirow[t]{2}{*}{ White } & 62.9 (62.6 to 63.2) & Reference & Reference \\
\hline & $65.1(64.2$ to 65.9$)$ & $1.10(1.06$ to 1.14$)$ & 0.97 (0.94 to 1.00$)$ \\
\hline Any other white & 57.5 (56.9 to 58.1 ) & 0.80 (0.78 to 0.82 ) & 1.03 (1.01 to 1.05 ) \\
\hline \multirow[t]{4}{*}{ Mixed } & 56.8 (54.8 to 58.9 ) & 0.78 (0.72 to 0.84$)$ & 1.05 (0.97 to 1.14 ) \\
\hline & $52.2(49.6$ to 54.7$)$ & 0.64 (0.58 to 0.71$)$ & 0.92 (0.84 to 1.02 ) \\
\hline & 56.7 (53.8 to 59.6 ) & 0.77 (0.69 to 0.87$)$ & 1.07 (0.99 to 1.16$)$ \\
\hline & 59.7 (57.7 to 61.7) & 0.88 (0.81 to 0.95$)$ & 1.09 (1.02 to 1.18 ) \\
\hline South-Asian & $63.0(62.2$ to 63.9$)$ & 1.01 (0.97 to 1.04 ) & $1.49(1.45$ to 1.53$)$ \\
\hline Pakistani & 61.4 (60.4 to 62.4$)$ & 0.94 (0.90 to 0.98 ) & $1.49(1.43$ to 1.54$)$ \\
\hline Bangladeshi & 61.7 (60.2 to 63.2 ) & 0.95 (0.89 to 1.01$)$ & 1.74 (1.64 to 1.84$)$ \\
\hline Any other Asian & 59.0 (57.9 to 60.1$)$ & 0.85 (0.81 to 0.89 ) & 1.28 (1.23 to 1.33$)$ \\
\hline Black Caribbean & $61.9(60.9$ to 62.8$)$ & 0.96 (0.92 to 1.00$)$ & 1.14 (1.10 to 1.18$)$ \\
\hline Black African & 47.3 (46.4 to 48.2 ) & 0.53 (0.51 to 0.55 ) & 0.81 (0.78 to 0.83 ) \\
\hline Any other black & $59.1(57.2$ to 61.1$)$ & 0.86 (0.79 to 0.93 ) & 1.08 (0.99 to 1.17$)$ \\
\hline Chinese & 48.5 (47.0 to 50.0 ) & 0.56 (0.52 to 0.59 ) & 0.86 (0.81 to 0.90 ) \\
\hline Other ethnic group & 58.5 (57.9 to 59.1$)$ & 0.83 (0.81 to 0.85 ) & $1.14(1.12$ to 1.17$)$ \\
\hline \multicolumn{4}{|l|}{ Deprivation quintile } \\
\hline 1 (affluent) & $64.1(63.7$ to 64.5$)$ & Reference & Reference \\
\hline 2 & $63.3(62.9$ to 63.6$)$ & 0.96 (0.95 to 0.98 ) & $0.96(0.95$ to 0.97$)$ \\
\hline 3 & $62.2(61.8$ to 62.6$)$ & $0.92(0.90$ to 0.94$)$ & $0.92(0.91$ to 0.93$)$ \\
\hline 4 & 61.0 (60.6 to 61.3 ) & 0.87 (0.86 to 0.89$)$ & 0.89 (0.88 to 0.90$)$ \\
\hline 5 (deprived) & 59.5 (59.1 to 60.0) & 0.82 (0.81 to 0.84 ) & 0.84 (0.83 to 0.85 ) \\
\hline \multicolumn{4}{|l|}{ Presence of self-reported chronic medical condition } \\
\hline No & 52.1 (51.7 to 52.4 ) & Reference & Reference \\
\hline Yes & $74.8(74.5$ to 75.0$)$ & $2.73(2.70$ to 2.76$)$ & $1.87(1.86$ to 1.89$)$ \\
\hline \multicolumn{4}{|c|}{ Presence of self-reported long-standing psychological or emotional condition } \\
\hline No & $61.3(61.1$ to 61.6$)$ & Reference & Reference \\
\hline Yes & 78.3 (77.9 to 78.7 ) & 2.28 (2.23 to 2.33 ) & 1.59 (1.57 to 1.62$)$ \\
\hline \multicolumn{4}{|l|}{ Number of practice GPs } \\
\hline 1 & $56.4(55.6$ to 57.2$)$ & $0.94(0.90$ to 0.97$)$ & $1.01(0.97$ to 1.05$)$ \\
\hline 2 & $58.0(57.4$ to 58.6$)$ & Reference & Reference \\
\hline 3 & $61.9(61.3$ to 62.5$)$ & $1.18(1.13$ to 1.22$)$ & $1.20(1.15$ to 1.25$)$ \\
\hline 4 & $63.5(62.9$ to 64.1$)$ & $1.26(1.22$ to 1.30$)$ & 1.29 (1.24 to 1.35$)$ \\
\hline 5 & $63.6(63.0$ to 64.2$)$ & $1.26(1.22$ to 1.31$)$ & $1.31(1.26$ to 1.37$)$ \\
\hline $6-9$ & $63.0(62.6$ to 63.4$)$ & $1.23(1.19$ to 1.27$)$ & $1.30(1.25$ to 1.34$)$ \\
\hline$\geq 10$ & $62.2(60.7$ to 63.6$)$ & $1.19(1.11$ to 1.27$)$ & $1.28(1.19$ to 1.37$)$ \\
\hline \multicolumn{4}{|l|}{ Type of appointments sought in previous 6 months $^{c}$} \\
\hline No appointments requested & $47.5(47.2$ to 47.8$)$ & $0.65(0.64$ to 0.66$)$ & 0.67 (0.66 to 0.68 ) \\
\hline Urgent only & $58.3(58.0$ to 58.6 ) & Reference & Reference \\
\hline Non-urgent only & $67.5(67.1$ to 67.9$)$ & $1.49(1.46$ to 1.51$)$ & $1.40(1.39$ to 1.42$)$ \\
\hline Both urgent and non-urgent & 73.5 (73.2 to 73.7 ) & $1.98(1.96$ to 2.00$)$ & $1.85(1.83$ to 1.87$)$ \\
\hline
\end{tabular}


and $75 \%$ respectively) when compared to those without $(66 \%$ and $72 \%$ respectively).
White patients were more likely to be able to see the doctor of their choice, compared to

Table 3. Prevalence and adjusted odds ratios for seeing a preferred doctor most of the time

\begin{tabular}{|c|c|c|c|c|}
\hline \multicolumn{2}{|l|}{ Characteristic } & $\begin{array}{c}\text { Weighted prevalence } \\
\qquad(95 \% \mathrm{Cl})\end{array}$ & $\begin{array}{l}\text { Crude weighted } \\
\text { OR }^{\mathrm{a}}(95 \% \mathrm{Cl})\end{array}$ & $\begin{array}{l}\text { Adjusted OR } \\
\text { (95\% CI) }\end{array}$ \\
\hline \multicolumn{2}{|l|}{ All survey responders } & 71.8 (71.4 to 72.1 ) & N/A & $\mathrm{N} / \mathrm{A}$ \\
\hline \multicolumn{5}{|l|}{ Sex } \\
\hline \multirow{2}{*}{\multicolumn{2}{|c|}{$\begin{array}{l}\text { Male } \\
\text { Female }\end{array}$}} & 73.6 (73.2 to 74.0 ) & Reference & Reference \\
\hline & & 70.2 (69.9 to 70.6 ) & 0.85 (0.84 to 0.86$)$ & 0.87 (0.86 to 0.88 ) \\
\hline \multicolumn{5}{|l|}{ Age group, years } \\
\hline \multicolumn{2}{|l|}{$18-24$} & 59.8 (59.1 to 60.5) & $0.43(0.42$ to 0.44$)$ & 0.43 (0.42 to 0.44 ) \\
\hline \multicolumn{2}{|l|}{$25-34$} & 60.2 (59.7 to 60.8) & $0.44(0.43$ to 0.44$)$ & $0.48(0.47$ to 0.49$)$ \\
\hline \multicolumn{2}{|l|}{$35-44$} & $63.6(63.1$ to 64.0$)$ & 0.50 (0.49 to 0.51$)$ & 0.54 (0.53 to 0.55 ) \\
\hline \multicolumn{2}{|l|}{$45-54$} & 69.8 (69.4 to 70.3 ) & $0.67(0.66$ to 0.68$)$ & 0.68 (0.67 to 0.69$)$ \\
\hline \multicolumn{2}{|l|}{$55-64$} & 77.7 (77.3 to 78.1$)$ & Reference & Reference \\
\hline \multicolumn{2}{|l|}{$65-74$} & 84.3 (84.0 to 84.7 ) & 1.55 (1.52 to 1.58$)$ & 1.53 (1.50 to 1.56$)$ \\
\hline \multicolumn{2}{|l|}{$75-84$} & 86.5 (86.1 to 86.8 ) & $1.84(1.80$ to 1.87$)$ & 1.82 (1.79 to 1.86$)$ \\
\hline \multicolumn{2}{|l|}{$\geq 85$} & 85.3 (84.8 to 85.7 ) & $1.66(1.61$ to 1.72$)$ & $1.56(1.51$ to 1.61$)$ \\
\hline \multirow{2}{*}{\multicolumn{2}{|c|}{$\begin{array}{l}\text { Ethnic group (ONS 6) } \\
\text { White }\end{array}$}} & & & \\
\hline & White British & $73.7(73.4$ to 74.1$)$ & Reference & Reference \\
\hline & Irish & 74.1 (73.2 to 75.1$)$ & $1.02(0.97$ to 1.07$)$ & 0.90 (0.86 to 0.94 ) \\
\hline & Any other white & $66.9(66.2$ to 67.5$)$ & $0.72(0.70$ to 0.74$)$ & 0.85 (0.83 to 0.88 ) \\
\hline \multirow[t]{4}{*}{ Mixed } & White and Black Caribbean & 61.8 (59.1 to 64.4 ) & $0.58(0.52$ to 0.64$)$ & 0.90 (0.81 to 1.00 ) \\
\hline & White and Black African & 56.6 (53.4 to 59.8 ) & $0.46(0.41$ to 0.53$)$ & 0.68 (0.60 to 0.78 ) \\
\hline & White and Asian & $63.4(60.7$ to 66.1$)$ & $0.62(0.55$ to 0.69$)$ & 0.81 (0.72 to 0.90$)$ \\
\hline & Any other mixed & $62.4(60.1$ to 64.7$)$ & 0.59 (0.54 to 0.65$)$ & 0.74 (0.67 to 0.81 ) \\
\hline \multirow[t]{4}{*}{ South-Asian } & Indian & $60.7(59.3$ to 62.1$)$ & 0.55 (0.52 to 0.58 ) & 0.73 (0.71 to 0.76$)$ \\
\hline & Pakistani & 54.4 (52.9 to 55.9 ) & $0.43(0.40$ to 0.45$)$ & 0.66 (0.63 to 0.69$)$ \\
\hline & Bangladeshi & 50.2 (48.1 to 52.3 ) & $0.36(0.33$ to 0.39$)$ & $0.57(0.53$ to 0.61$)$ \\
\hline & Any other Asian & $56.8(55.4$ to 58.1$)$ & $0.47(0.44$ to 0.49$)$ & 0.59 (0.56 to 0.62 ) \\
\hline \multirow[t]{3}{*}{ Black } & Black Caribbean & $65.6(64.2$ to 67.0$)$ & 0.68 (0.64 to 0.72$)$ & 0.83 (0.79 to 0.87 ) \\
\hline & Black African & 52.3 (50.9 to 53.8 ) & 0.39 (0.37 to 0.42$)$ & 0.55 (0.53 to 0.58 ) \\
\hline & Any other black & 58.0 (55.3 to 60.6$)$ & 0.49 (0.44 to 0.55$)$ & 0.70 (0.62 to 0.78 ) \\
\hline Chinese & Chinese & $56.2(54.1$ to 58.4$)$ & $0.46(0.42$ to 0.50$)$ & 0.55 (0.51 to 0.59 ) \\
\hline & Other ethnic group & 60.6 (59.9 to 61.4 ) & 0.55 (0.53 to 0.57 ) & 0.66 (0.64 to 0.68 ) \\
\hline \multicolumn{5}{|l|}{ Deprivation quintile } \\
\hline 1 (affluent) & & 74.3 (73.7 to 74.8 ) & Reference & Reference \\
\hline 2 & & 74.1 (73.6 to 74.6$)$ & 0.99 (0.97 to 1.02 ) & 0.99 (0.97 to 1.01 ) \\
\hline 3 & & 72.3 (71.8 to 72.8 ) & 0.90 (0.88 to 0.93 ) & 0.95 (0.94 to 0.97 ) \\
\hline 4 & & $69.6(69.1$ to 70.1$)$ & 0.79 (0.77 to 0.82 ) & 0.91 (0.89 to 0.93 ) \\
\hline 5 (deprived) & & $67.0(66.4$ to 67.6$)$ & 0.70 (0.68 to 0.73$)$ & 0.86 (0.84 to 0.88 ) \\
\hline Presence of self-repo & chronic medical condition & & & \\
\hline No & & 66.3 (65.8 to 66.7) & Reference & Reference \\
\hline Yes & & 76.8 (76.4 to 77.1$)$ & $1.68(1.66$ to 1.70$)$ & 1.29 (1.27 to 1.30$)$ \\
\hline Presence of self-repo & long-standing psychological & hotional condition & & \\
\hline No & & 71.9 (71.5 to 72.2 ) & Reference & Reference \\
\hline Yes & & 75.3 (74.8 to 75.8 ) & $1.19(1.17$ to 1.22$)$ & 1.25 (1.22 to 1.27$)$ \\
\hline Number of practice $G$ & & & & \\
\hline 1 & & $78.5(77.3$ to 79.6$)$ & $1.10(1.01$ to 1.19$)$ & 1.42 (1.33 to 1.52$)$ \\
\hline 2 & & 76.9 (76.0 to 77.7$)$ & Reference & Reference \\
\hline 3 & & 74.5 (73.6 to 75.4 ) & $0.88(0.82$ to 0.94$)$ & $0.76(0.71$ to 0.81$)$ \\
\hline 4 & & 73.4 (72.6 to 74.3 ) & 0.83 (0.78 to 0.89$)$ & 0.66 (0.61 to 0.70$)$ \\
\hline 5 & & 72.0 (71.1 to 72.9 ) & 0.77 (0.73 to 0.83 ) & $0.57(0.53$ to 0.61$)$ \\
\hline $6-9$ & & 69.7 (69.2 to 70.3 ) & 0.69 (0.66 to 0.73 ) & $0.48(0.45$ to 0.51$)$ \\
\hline$\geq 10$ & & $68.8(67.0$ to 70.7$)$ & $0.67(0.60$ to 0.74$)$ & $0.44(0.40$ to 0.49$)$ \\
\hline Type of appointments & ght in previous 6 months ${ }^{c}$ & & & \\
\hline No appointments req & & 73.6 (73.2 to 74.0 ) & $1.23(1.21$ to 1.25$)$ & $1.17(1.15$ to 1.19$)$ \\
\hline Urgent only & & 69.4 (68.9 to 69.8) & Reference & Reference \\
\hline Non-urgent only & & 78.8 (78.4 to 79.2 ) & $1.64(1.60$ to 1.68$)$ & 1.59 (1.57 to 1.62$)$ \\
\hline Both urgent and non- & ent & 70.3 (69.9 to 70.7$)$ & $1.05(1.03$ to 1.06$)$ & $1.12(1.10$ to 1.13$)$ \\
\hline
\end{tabular}




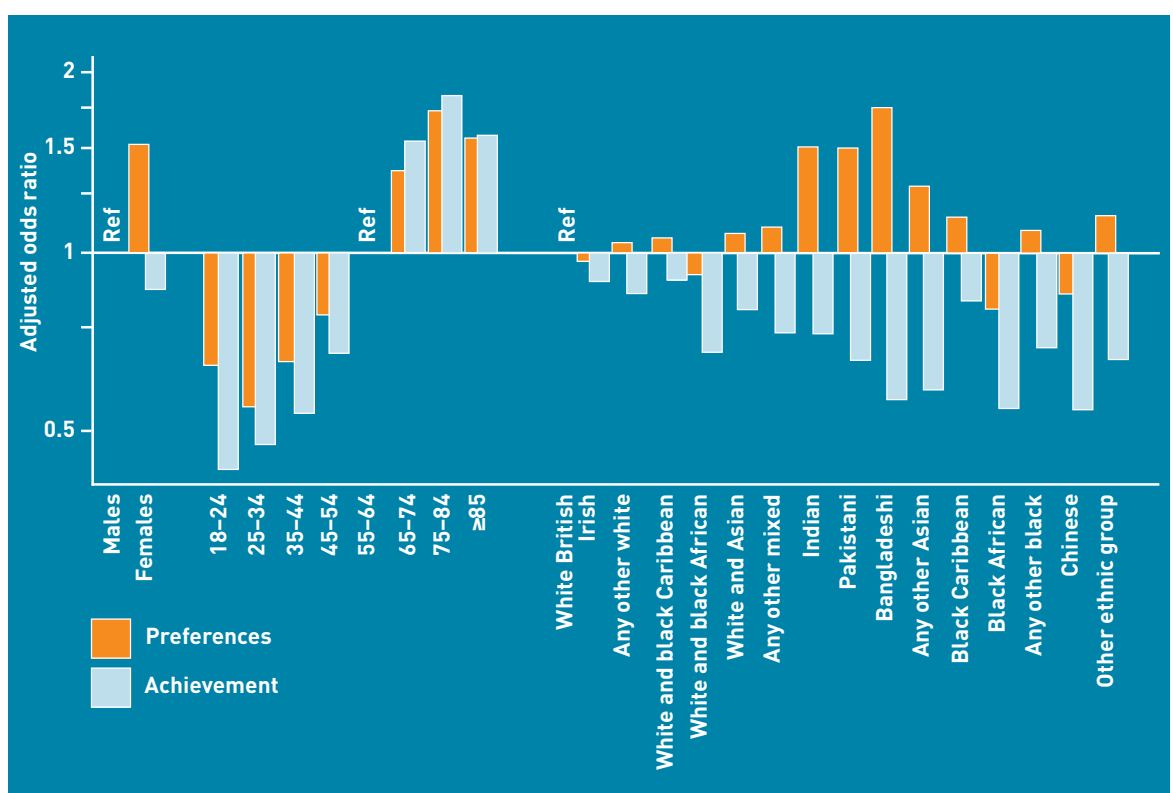

Figure 1. Adjusted odds ratios of having preference for seeing a particular doctor, and success in achieving it most of the time (sex, age, and ethnicity).

Figure 2. Adjusted odds ratios of having preference for seeing a particular doctor, and success in achieving it most of the time (deprivation, chronic conditions, practice size, and appointment type). most other ethnic groups. More deprived patients were less successful in seeing the doctor they preferred most of the time $167 \%$ for the most-deprived, rising to $74 \%$ for the least-deprived patients). Success in seeing a particular doctor decreased as the number of practice GPs increased (77\% for practices with 10 or more GPs). Success in seeing a particular doctor was least among patients requesting urgent appointments only (69\%), where it was greatest for patients requesting only non-urgent appointments (79\%). The crude odds ratios (Table 3) reflect the associations described above. All associations are stronger than would be expected by chance $(P<0.001)$.

In multivariate analysis, there was strong practices with two GPs compared to 69\% for evidence that differences in the success of seeing a preferred doctor persist after adjusting for other factors $(P<0.001$ for all variables) (Table 3). Female patients were less likely to be successful than males in seeing the doctor of their preference $10 R=$ 0.87). This contrasts with older patients (OR $=1.82$ for age group 74-85 years compared to age group 55-64 years), those with a chronic medical $(O R=1.29)$ or psychological/emotional condition (OR = 1.25), and white patients, all of whom were more likely to be successful compared to their respective reference groups. Success in seeing a preferred doctor was also less common in deprived areas $1 \mathrm{OR}=0.86$ for most deprived compared to most affluent). Patients registered with larger practices were less likely to report that they could see a doctor of their choice most of the time lOR $=0.48$ for patients registered with practices with six to nine GPs compared to patients registered with practices with two GPs). Patients who requested only non-urgent appointments were more likely to be successful in seeing the doctor they prefer lOR $=1.59$ compared to patients requesting only urgent appointments). The odds ratios from Tables 2 and 3 are summarised in Figures 1 and 2 .

\section{DISCUSSION}

\section{Summary}

About two-thirds of English patients have a preference for seeing a particular doctor, and of these patients, about three-quarters succeed in seeing their preferred doctor most of the time. This figure reflects some success of English general practice in meeting patients' preferences for continuity, but also represents an opportunity for improvement for more than one-quarter of patients who found it difficult to see the doctor of their choice most of the time.

The preference for and success in seeing a particular doctor varied across patient groups. Females, older people, patients with long-term conditions, and South Asian individuals were more likely to prefer to see a particular doctor. Males, older patients, those with long-term conditions, and white patients reported more success in seeing their preferred doctor. Patients requesting urgent appointments were less likely to want to see a particular doctor. This may reflect a greater value placed by patients on swift access to medical care in the context of acute/urgent conditions. However, patients making urgent appointments were also less likely to succeed in doing so if they did want to see a particular doctor, reflecting the 
difficulty for practices in offering speedy access and continuity of care simultaneously.

In spite of their higher preference for relational continuity, South Asian individuals land to a lesser extent females and patients from large practices) were less likely to be successful in seeing a particular doctor. One possible reason why South Asian patients report such disadvantage in seeing their preferred doctor could be that, for some, their first language is not English, making them less able to negotiate with the receptionists in order to book an appointment to see their preferred doctor.

The findings suggest that relational continuity is preferred and achieved more frequently by older patients and those with chronic conditions. These patients are more likely to request appointments in advance (for example, for managing a chronic condition) compared to younger healthier patients (who are likely to request appointments for acute conditions). However, because the study analysis was adjusted for appointment type, it is not likely that the observed relation between age and health conditions on one side and preferring and achieving continuity on the other is confounded by the type of appointments sought.

Although the analysis was restricted to the $98 \%$ of responders who reported that their practice had more than one doctor, one in eight responders were registered with a practice recorded by the NHS Information Centre as being 'single-handed'. It is likely that these patients were attending practices formally recorded as having just one practice doctor but in which other doctors also worked from time to time (for example, in assistant, salaried or locum capacity).

\section{Strengths and limitations}

Most previous evidence on variation in continuity of care comes from relatively small studies. The present study increases the evidence base substantially, with its large national sample of 2.2 million responders. This allowed the independent associations of a large number of different sociodemographic variables to be estimated robustly.

Caution should be applied when interpreting the results of the GPPS, due to its relatively low response rate (39\%), with the mean response rate being lower than $25 \%$ in some primary care trusts. Significant sociodemographic differences in patterns of non-response have also been reported, with males, young adults, and people living in deprived areas being under-represented among responders..$^{17}$ To minimise the effect of selective non-response bias, all prevalence estimates were weighted using weights accounting for oversampling from small practices and from practices with low response rates, as well as for individual nonresponse patterns (by age, sex, and practice). These weights, however, would not have accounted for any systematic difference in experiences of continuity between responders and non-responders that were not associated with these factors.

Given the wording of question 15 ('Is there a particular doctor you prefer to see at your GP surgery or health centre?'), it is possible that some patients who value continuity might reply 'No' to this question, because they have no preference for seeing a particular doctor. This might apply, for example, to individuals with no recent encounters or those who value all doctors equally but still prefer to see the same doctor regularly. To that extent, it is possible that the true prevalence of preference for interpersonal continuity was underestimated in this survey. Some patients may also have a preference to avoid seeing a specific doctor las opposed to seeing a particular one). Other patients may have a preference for seeing different doctors for different aspects of their care, for example, a particular doctor for the management of a mental health condition and another for a physical health problem. Such preferences could affect patients' desire for and success in achieving relational continuity. The wording of the survey questions, however (Box 2), does not allow examination of such aspects of preference for relational continuity.

\section{Comparison with existing literature}

In a paper produced by The King's Fund, ${ }^{22}$ Freeman and Hughes used the 2008/2009 GPPS results to assess patients and clinicians' perspectives on continuity. Descriptive analysis was performed to identify the proportion of patients who want to see their preferred doctor and those who could achieve this. Variation by age, sex, ethnicity, chronic disease status, and practice size was in agreement with the findings of the present study. The present study took the analysis further by conducting multivariate analyses to adjust for potential confounding by sociodemographic variables and appointment type. In accordance with previous research, the present study indicates that interpersonal continuity of care is valued by the majority of patients, especially females, older patients, and those with chronic diseases. ${ }^{7.8}$ Previous studies similarly suggest that males, older patients, 
white patients, and those registered with small practices are more likely to receive continuity of care. ${ }^{22-28}$

\section{Implications for research and practice}

Continuity of care can be viewed from the perspective of the patient, the doctor, or the healthcare system. ${ }^{29}$ This study takes the patient's perspective and confirms that interpersonal continuity of care is valued by patients. However, by no means all patients expressed this preference. Some patients will prefer rapid access to appointments, but in other situations they may trade off rapid access for better continuity. ${ }^{30,31}$ This underscores an important aspect of healthcare quality, which is the need to provide a system that is sensitive to the needs of individual patients. Practices need to provide flexible appointment systems that offer a choice between continuity of care and rapid access to appointments.

However, there is a substantial minority of patients, up to one-quarter, who, most of the time, are not successful in seeing their preferred doctor. This is particularly important, given the evidence that continuity of care has declined in recent years. ${ }^{14-16}$ There are a number of possible reasons for this, including a focus on access and rapid appointments in the 2004 GP contract. increasing part-time working among doctors, and an increase in salaried land potentially transient) GPs. The larger medical teams now present in many general practices also make personal continuity more difficult to achieve. ${ }^{32}$

There are clear messages here for the organisation of general practice. Continuity of care is valued by patients, and is said to be highly valued by GPs as well. ${ }^{33}$ If interpersonal continuity of care is indeed a core value of general practice, then more needs to be done to ensure that continuity is reflected in the service that practices offer to patients. Government, the Department of Health, and commissioning groups, in turn, should work together to support and incentivise practices to improve patients' experiences through fostering continuity of care. 


\section{REFERENCES}

1. Haggerty JL, Reid RJ, Freeman GK, et al. Continuity of care: a multidisciplinary review. BMJ 2003; 327(7425): 1219-1221.

2. Wall EM. Continuity of care and family medicine: definition, determinants, and relationship to outcome. J Fam Pract 1981; 13(5): 655-664.

3. Starfield B. Continuous confusion? Am J Public Health 1980; 70(2): 117-119.

4. Banahan BF Jr, Banahan BF III. Continuity as an attitudinal contract. J Fam Pract 1981; 12(4): 767-778

5. Freeman G. Continuity of care in general practice: a review and critique. Fam Pract 1984; 1(4): 245-252.

6. Freeman $G$, Hjortdahl P. What future for continuity of care in general practice? BMJ 1997; 314(7098): 1870-1873.

7. Turner $D$, Tarrant $C$, Windridge $K$, et al. Do patients value continuity of care in general practice? An investigation using stated preference discrete choice experiments. J Health Serv Res Policy 2007; 12(3): 132-137.

8. Pandhi N, Saultz JW. Patients perceptions of interpersonal continuity of care. J Am Board Fam Med 2006; 19(4): 390-397.

9. Saultz JW, Lochner J. Interpersonal continuity of care and care outcomes: a critical review. Ann Fam Med 2005; 3(2): 159-166.

10. Hsiao CJ, Boult C. Effects of quality on outcomes in primary care: a review of the literature. Am J Med Qual 2008; 23(4): 302-310.

11. Hjortdahl P. Laerum E. Continuity of care in general practice: effect on patient satisfaction. BMJ 1992; 304(6837): 1287-1290.

12. Weyrauch KF. Does continuity of care increase $\mathrm{HMO}$ patients' satisfaction with physician performance? J Am Board Fam Pract 1996; 9(1): 31-36.

13. Wasson JH, Sauvigne AE, Mogielnicki RP, et al. Continuity of outpatient medical care in elderly men. A randomized trial. JAMA 1984; 252(17): 2413-2417.

14. Emanuel EJ, Dubler NN. Preserving the physician-patient relationship in the era of managed care. JAMA 1995; 273(4): 323-329.

15. Guthrie B, Wyke S. Does continuity in general practice really matter? BMJ 2000; 321(7263): 734-736.

16. Campbell SM, Kontopantelis E, Reeves D, et al. Changes in patient experiences of primary care during health service reforms in England between 2003 and 2007. Ann Fam Med 2010; 8(6): 499-506.

17. Roland M, Elliott M, Lyratzopoulos G, et al. Reliability of patient responses in pay for performance schemes: analysis of national General Practitioner Patient Survey data in England. BMJ 2009; 339: b3851.

18. Campbell J, Smith P, Nissen S, et al. The GP Patient Survey for use in primary care in the National Health Service in the UK - development and psychometric characteristics. BMC Fam Pract 2009; 10: 57

19. Ipsos MORI. Technical annex for the GP Patient Survey 2009/10 annual report. http://gp-patient.co.uk/results/annual/technicalannex200910 (accessed 7 Jun 2012).

20. Ipsos MORI. The GP Patient Survey. http://unw.gp-patient.co.uk laccessed 7 Jun 2012).

21. Noble M, McLennan D, Wilkinson K, et al. The English Indices of Deprivation 2007 London: Department of Communities and Local Government, 2008.

http://unw.communities.gov.uk/documents/communities/pdf/733520.pdf laccessed 12 Ju1 2012).

22. Freeman $G$, Hughes J. Continuity of care and the patient experience. London: The King's Fund, 2010

23. Baker R, Boulton M, Windridge $\mathrm{K}$, et al. Interpersonal continuity of care: a crosssectional survey of primary care patients preferences and their experiences. $\mathrm{Br} \mathrm{J}$ Gen Pract 2007; 57(537): 283-289.

24. Boulton M, Tarrant $\mathrm{C}$, Windridge $\mathrm{K}$, et al. How are different types of continuity achieved? A mixed methods longitudinal study. Br J Gen Pract 2006; 56(531): 749-755.

25. Mead N, Roland M. Understanding why some ethnic minority patients evaluate medical care more negatively than white patients: a cross sectional analysis of a routine patient survey in English general practices. BMJ 2009; 339: b3450.

26. Campbell JL, Ramsay J, Green J. Age, gender, socioeconomic, and ethnic differences in patients' assessments of primary health care. Qual Health Care 2001; 10(2): 90-95.

27. Campbell JL, Ramsay J, Green J. Practice size: impact on consultation length, workload, and patient assessment of care. Br J Gen Pract 2001; 51(469): 644-650.

28. Kontopantelis E, Roland M, Reeves D. Patient experience of access to primary care: identification of predictors in a national patient survey. BMC Fam Pract 2010; 11: 61.

29. Salisbury C, Sampson F, Ridd M, Montgomery A. How should continuity of care in primary health care be measured? Br J Gen Pract 2009; 50(561): e134-141.

30. Guthrie B, Wyke S. Personal continuity and access in UK general practice: a qualitative study of general practitioners' and patients' perceptions of when and how they matter. BMC Fam Pract 2006; 7: 11

31. Gerard K, Salisbury C, Street D, et al. Is fast access to general practice all that should matter? A discrete choice experiment of patient preferences. J Health Serv Res Policy 2008; 13(suppl 2): 3-10.

32. Wagner EH, Reid RJ. Are continuity of care and teamwork incompatible? Med Care 2007; 45(1): 6-7.

33. Ridd M, Shaw A, Salisbury C. 'Two sides of the coin' - the value of personal continuity of GPs: a qualitative interview study. Fam Pract 2006; 23(4): 461-468. 